\title{
Antifolates inhibit Cryptococcus biofilms and enhance susceptibility of planktonic cells to amphotericin B
}

\author{
R. de Aguiar Cordeiro • C. I. Mourão • M. F. G. Rocha • F. J. de Farias \\ Marques - C. E. C. Teixeira - D. F. de Oliveira Miranda • L. V. P. Neto • \\ R. S. N. Brilhante • T. de Jesus Pinheiro Gomes Bandeira • J. J. C. Sidrim
}

Received: 15 August 2012 / Accepted: 29 October 2012 / Published online: 29 November 2012

(C) Springer-Verlag Berlin Heidelberg 2012

\begin{abstract}
The Cryptococcus neoformans species complex contains the most important agents of fungal meningoencephalitis. Therapeutic choices are limited and issues related to toxicity and resistance to antifungals have been described. The present study evaluated the inhibitory effect of the antifolate combinations sulfamethoxazole-trimethoprim (SMX/TMP) and sulfadiazine-pyrimethamine (SDZ/PYR) against planktonic cells and biofilms of $C$. neoformans and $C$. gattii. The influence of the antifolate combinations on the amphotericin minimum inhibitory concentration (MIC) of planktonic cells was also investigated. In addition, the effect of these combinations on the cellular ergosterol content of planktonic cells was studied. Strains of $C$. neoformans $(n=15)$ and $C$. gattii $(n=15)$ obtained from environmental or clinical sources were evaluated by the broth microdilution method. SMX/TMP and SDZ/PYR showed antifungal activity against free living cells and sessile cells of Cryptococcus spp. Moreover, planktonic
\end{abstract}

R. de Aguiar Cordeiro $(\varangle) \cdot$ C. I. Mourão • M. F. G. Rocha •

F. J. de Farias Marques $\cdot$ C. E. C. Teixeira

D. F. de Oliveira Miranda - L. V. P. Neto • R. S. N. Brilhante •

T. de Jesus Pinheiro Gomes Bandeira · J. J. C. Sidrim

Department of Pathology and Legal Medicine, School

of Medicine, Postgraduate Program in Medical Microbiology

and Specialized Medical Mycology Center,

Federal University of Ceará,

Fortaleza, CE, Brazil

e-mail: rossanacordeiro@ufc.br

R. de Aguiar Cordeiro • C. I. Mourão • R. S. N. Brilhante •

J. J. C. Sidrim

Department of Clinical Medicine, School of Medicine,

Post-Graduation Program in Medicine Science,

Federal University of Ceará,

Fortaleza, CE, Brazil

M. F. G. Rocha

School of Veterinary Medicine, Postgraduate Program

in Veterinary Science, State University of Ceará,

Fortaleza, CE, Brazil cells showed increased susceptibility to amphotericin B after pre-incubation with sub-inhibitory concentrations of SMX/ TMP or SDZ/PYR. The drug combinations SMX/TMP and SDZ/PYR were able to prevent the biofilm formation and showed inhibitory effect against mature biofilms of both species. Additionally, the study showed that antifolate drugs reduced the ergosterol content in C. neoformans and C. gattii planktonic cells. Our results highlight the antifungal potential of antifolate drugs.

\section{Introduction}

Cryptococcosis is a life-threatening disease caused by the Cryptococcus neoformans species complex, which is formed by $C$. neoformans (serotypes $\mathrm{A}, \mathrm{D}$, and $\mathrm{A} / \mathrm{D}$ ) and C. gattii (serotypes B and C), commonly acquired by inhalation of conidia from the air and bird droppings [1]. Primary infection usually results in pneumonia or dissemination to the central nervous system [2]. Cryptococcal meningitis is considered to be one of the most important human immunodeficiency virus (HIV)-related opportunistic infections, and it is estimated that around 1 million cases occur globally per year in acquired immunodeficiency syndrome (AIDS) patients $[2,3]$.

The treatment of cryptococcal meningoencephalitis relies mainly on amphotericin B, alone or associated with 5fluorocytosine [2,4]. However, nephrotoxicity and renal dysfunction have often been reported among patients under therapeutic regimens with this antifungal [4]. In order to overcome these issues, fluconazole is considered as an alternative for induction and consolidation, maintenance, or prophylactic therapy $[2,5]$. Although antifungal resistance in Cryptococcus is not considered to be a main problem worldwide [6], some studies have shown that resistance can be a problem in developing countries $[5,7]$. Moreover, the 
heteroresistance to fluconazole and its linkage to virulence among clinical Cryptococcus strains have gained attention in recent years $[5,8]$. To address these problems, much effort has been devoted to searching for new antifungals against Cryptococcus [9-11].

Additionally, many studies have shown that Cryptococcus spp. have the ability to colonize and form biofilms in medical devices [12-15]. Fungal biofilms are formed by microbial communities associated with an extracellular matrix and their development is controlled by complex molecular events [13]. These structures have been associated with infection with high levels of therapeutic refractoriness - due to their intrinsic antifungal resistance - as well as being associated with significant mortality [13]. However, despite the great importance of the topic, few studies have investigated strategies to control and eradicate Cryptococcus biofilms [14-16]. The insertion of medical devices, such as ventriculoatrial shunt catheters [17, 18], prosthetic valves [19], and prosthesis [20], are related to Cryptococcus biofilm formation.

The present study aimed to evaluate the inhibitory effect of the antimicrobial combinations sulfamethoxazole-trimethoprim (SMX/TMP) and sulfadiazine-pyrimethamine (SDZ/ PYR) against planktonic cells and biofilms of $C$. neoformans and $C$. gattii. The effect of these drugs on the cellular ergosterol content and on the antifungal susceptibility of planktonic cells to amphotericin B was also investigated.

\section{Materials and methods}

\section{Microorganisms}

Strains of C. neoformans $(n=15)$ and C. gattii $(n=15)$ were obtained from environmental or clinical sources. The use of clinical strains was approved by the Ethics Committee of São José Hospital of Infectious Diseases (Fortaleza, Ceará, Brazil; Process 007-2009). The identification of C. neoformans and C. gattii was based on the following phenotypical characteristics: urease test on Christensen's urea agar (Difco Laboratories, England); phenoloxidase activity on birdseed agar (Guizotia abyssinica) supplemented with biphenyl (0.1\%); and chemotyping on CGB medium (L-canavanine, glycine, bromothymol blue), as previously described [21]. In addition, molecular characterization of each serotype was performed as described by Enache-Angoulvant et al. [22], through enzymatic restriction of the CAP59 gene. Eight reference strains, obtained from Evandro Chagas Clinical Research Institute, Brazil (IPEC/FIOCRUZ), were used as controls: C. neoformans var. grubii WM 148 (serotype A, VNI/AFLP1), C. neoformans var. grubii WM 626 (serotype A, VNII/AFLP1A), C. neoformans WM 628 (serotype AD, VNIII/AFLP2), C. neoformans var. neoformans WM 629 (serotype D, VNIV/AFLP3), C. gattii WM 179 (serotype B,
VGI/AFLP4), C. gattii WM 178 (serotype B, VGII/AFLP6), C. gattii WM 175 (serotype B, VGIII/AFLP5), and C. gattii WM 779 (serotype C, VGIV/AFLP7) [23].

Antimicrobial drugs

Stock solutions of SMX/TMP and SDZ/PYR were prepared in $10 \%$ dimethyl sulfoxide (DMSO) and amphotericin B (AMB) was diluted in $100 \%$ DMSO. Serial two-fold dilutions of SMX/TMP and SDZ/PYR were prepared with yeast nitrogen base (YNB) medium [22]. AMB was diluted in RPMI 1640 medium with L-glutamine and without sodium bicarbonate (Sigma Chemical Co., St. Louis, MO, USA), buffered to $\mathrm{pH} 7.0$ with $0.165 \mathrm{M}$ morpholinepropanesulfonic acid (MOPS) (Sigma Chemical Co.).

Inoculum preparation for susceptibility testing

Inocula of all tested isolates were prepared from 48 -h-old cultures previously grown on potato dextrose agar at $35^{\circ} \mathrm{C}$. The colonies were suspended in $5 \mathrm{~mL}$ of sterile $0.9 \%$ saline and the turbidity was adjusted to 0.5 on the McFarland scale. Afterwards, the suspension was diluted 1:100 and then 1:20 with YNB medium to obtain an inoculum of planktonic cells containing $0.5-2.5 \times 10^{3}$ cells $/ \mathrm{mL}$ [24].

Antifungal susceptibility of Cryptococcus planktonic cells

Effect of SMX/TMP and SDZ/PYR on Cryptococcus growth

The effect of the combinations of SMX/TMP and SDZ/PYR against $C$. neoformans and $C$. gattii strains was investigated by broth microdilution, according to the Clinical and Laboratory Standards Institute (CLSI) document M27-A3 [25], except for the substitution of RPMI 1640 medium for YNB without PABA in this composition, because this component can interfere with the antifungal activity of sulpha drugs [24]. The final concentrations of each antimicrobial combination ranged as follows: 1.953 to $1,000 \mu \mathrm{g} / \mathrm{mL}$ for SMX and SDZ; 0.39 to $200 \mu \mathrm{g} / \mathrm{mL}$ for TMP; 0.098 to $50 \mu \mathrm{g} / \mathrm{mL}$ for PYR; and 0.015 to $8 \mu \mathrm{g} / \mathrm{mL}$ for AMB.

Susceptibility testing for planktonic cells was performed in 96-well microdilution plates at $37{ }^{\circ} \mathrm{C}$ for $48 \mathrm{~h}$. All the isolates were tested in duplicate. For SMX/TMP and SDZ/ PYR, the minimum inhibitory concentrations (MICs) were defined as the lowest drug concentration inhibiting growth by $80 \%$ when compared to the control well $[24,26]$.

Effect of sub-inhibitory concentrations of SMX/TMP and SDZ/PYR on susceptibility to amphotericin $B$

The effect of SMX/TMP and SDZ/PYR on the susceptibility of Cryptococcus to AMB was also investigated. For this 
purpose, strains of $C$. neoformans $(n=7)$ and $C$. gattii $(n=7)$ with previously known susceptibility patterns to AMB [27] were chosen.

A standardized inocula prepared as described above was incubated in YNB medium supplemented with SMX/TMP or SDZ/PYR at sub-inhibitory MIC (MIC/2) for $24 \mathrm{~h}$ at $37^{\circ} \mathrm{C}$ in an orbital shaker at $150 \mathrm{rpm}$. Controls were grown in YNB medium without antimicrobials. After incubation, cultures were centrifuged at 2,000 rpm for $5 \mathrm{~min}$. From the resulting pellet, an inoculum of $0.5-2.5 \times 10^{3}$ cells $/ \mathrm{mL}$ was prepared in $5 \mathrm{~mL}$ of sterile $0.9 \%$ saline and AMB MIC was determined by the CLSI M27-A3 broth microdilution method, using RPMI 1640 medium buffered to $\mathrm{pH} 7.0$ with 0.165 M MOPS [25]. The MIC for AMB was defined as the lowest concentration at which no growth was observed [25]. C. parapsilosis ATCC 22019 and C. krusei ATCC 6528 were used as quality control strains.

\section{Effect of SMX/TMP and SDZ/PYR on ergosterol content of planktonic cells}

Total sterols were extracted as described by Moran et al. [28], with modifications. Strains of $C$. neoformans $(n=7)$ and $C$. gattii $(n=7)$ were grown in potato dextrose agar for $48 \mathrm{~h}$ at $37^{\circ} \mathrm{C}$ and, after this period, a loopful of inoculum was transferred to YNB supplemented with SMX/TMP or SDZ/PYR at sub-MIC (MIC/2) for each drug combination. The tubes were incubated for $48 \mathrm{~h}$ at $37^{\circ} \mathrm{C}$ and then centrifuged at 12,000 rpm for $3 \mathrm{~min}$. Cellular pellets were suspended in $0.5 \mathrm{~mL}$ of alcoholic $\mathrm{KOH}(3.945 \mathrm{~g}$ of $\mathrm{KOH}$ and $40 \mathrm{ml}$ of sterile distilled water, brought to $100 \mathrm{ml}$ with $100 \%$ ethanol) and incubated for $1 \mathrm{~h}$ at $95{ }^{\circ} \mathrm{C}$. Following incubation, the tubes were allowed to cool and total sterols were extracted by the addition of $600 \mu \mathrm{L}$ of n-hexan and vigorous vortexing for $5 \mathrm{~min}$. The tubes were centrifuged at $10,443 \mathrm{rpm}$ for $1 \mathrm{~min}$ and the entire organic top layer was transferred to a new tube and mixed with $1 \mathrm{~mL}$ of $\mathrm{n}$-hexane. Absorbance readings were performed at $295 \mathrm{~nm}$. Ergosterol quantification was performed by comparison to the standard curve with ergosterol P.A. (Sigma-Aldrich, Germany). The experiments were performed in duplicate. The results were compared with the ergosterol content of cells grown in YNB without antifolate drugs; itraconazole ( $\mathrm{MIC} / 2)$ was used as a positive control.

\section{Biofilm formation}

For biofilm testing, inocula were prepared as described by Martinez et al. [9]. In brief, strains of $C$. neoformans $(n=7)$ and $C$. gattii $(n=7)$, randomly chosen from the set of clinical and environmental isolates, were grown in Sabouraud dextrose broth for $24 \mathrm{~h}$ at $30{ }^{\circ} \mathrm{C}$ in a rotary shaker at $150 \mathrm{rpm}$. After this period, the cells were collected by centrifugation and the pellet was washed two times with PBS. Suspensions were adjusted to $10^{7}$ cells $/ \mathrm{mL}$ in chemical medium $(20 \mathrm{mg} /$ $\mathrm{mL}$ thiamine, $30 \mathrm{mM}$ glucose, $26 \mathrm{mM}$ glycine, $20 \mathrm{mM}$ $\mathrm{MgSO}_{4} .7 \mathrm{H}_{2} \mathrm{O}, 58.8 \mathrm{mM} \mathrm{KH}_{2} \mathrm{PO}_{4}$ ) and then $100-\mu \mathrm{l}$ inoculum aliquots were transferred to flat wells of 96-well polystyrene plates. The plates were incubated at $37{ }^{\circ} \mathrm{C}$ for $48 \mathrm{~h}$ and then the wells were washed three times with $0.05 \%$ Tween 20 in Tris-buffered solution to remove non-adhered cells. Biofilm viability was monitored by the color change of resazurin solution $(0.1 \mathrm{mg} / \mathrm{mL}$ in RPMI) after incubation at $37^{\circ} \mathrm{C}$ for at least $6 \mathrm{~h}[29]$.

\section{Effect of SMX/TMP and SDZ/PYR against mature Cryptococcus biofilms}

The inhibitory activity of SMX/TMP and SDZ/PYR against Cryptococcus biofilms was evaluated according to Martinez et al. [9], with slight modifications. Aliquots of $200 \mu \mathrm{L}$ of each antimicrobial combination at two different concentrations were added to viable 48 -h biofilms as follows: SMX/SDZ at $5,000 \mathrm{mg} / \mathrm{L}-1,000 \mathrm{mg} / \mathrm{L}$ and $2,000 \mathrm{mg} / \mathrm{L}-400 \mathrm{mg} / \mathrm{L}$; SDZ/ TMP at $5,000 \mathrm{mg} / \mathrm{L}-250 \mathrm{mg} / \mathrm{L}$ and $2,000 \mathrm{mg} / \mathrm{L}-100 \mathrm{mg} / \mathrm{L}$.

Following incubation at $37{ }^{\circ} \mathrm{C}$ for $48 \mathrm{~h}$, the supernatant was aspirated and an aliquot of $100 \mu \mathrm{L}$ of $0.3 \%$ crystal violet was added to each well. After $5 \mathrm{~min}$ at $25^{\circ} \mathrm{C}$, the dye solution was aspirated and the wells were washed twice with sterile distilled water. The wells were filled with $200 \mu \mathrm{L}$ of $100 \%$ ethanol and, after $5 \mathrm{~min}$ at $25{ }^{\circ} \mathrm{C}$, the mixture was aspirated and read in a spectrophotometer at $550 \mathrm{~nm}$ [29]. The tests were conducted in duplicate; controls were grown in medium without antimicrobials. The effect of antifolate drugs was compared with $\mathrm{AMB}$, which is considered to be a strong inhibitor of Cryptococcus biofilms [14].

\section{Effect of SMX/TMP and SDZ/PYR in preventing $C$. neoformans biofilm formation}

In addition, the biofilm inhibition ability of SMX/TMP and SDZ/PYR were evaluated. Biofilm formation was conducted as previously described except for the addition of antifolates to the chemical medium at the following drug combinations: SMX/TMP at $5,000 \mathrm{mg} / \mathrm{L}-1,000 \mathrm{mg} / \mathrm{L}$ and $2,000 \mathrm{mg} / \mathrm{L}-400 \mathrm{mg} / \mathrm{L} ; \mathrm{SDZ} / \mathrm{PYR}$ at $5,000 \mathrm{mg} / \mathrm{L}-250 \mathrm{mg} / \mathrm{L}$ and $2,000 \mathrm{mg} / \mathrm{L}-100 \mathrm{mg} / \mathrm{L}$. Controls were grown in minimum medium without antimicrobials. Biofilm viability was monitored by resazurin metabolism and crystal violet dying [29], as described above.

Statistical analysis

The antimicrobial susceptibilities were compared using oneway analysis of variance (ANOVA) and Tukey's multiple comparison post-test. Differences between treatments were 
evaluated for significance using the Wilcoxon signed-rank test. A $p$-value $<0.05$ was considered to be significant. The statistical analyses were performed with GraphPad Prism 5.0 (GraphPad Software, San Diego, CA, USA).

\section{Results}

Effect of antifolate drug combinations on Cryptococcus planktonic cells

The susceptibility profile of Cryptococcus planktonic cells to antifolate drugs are shown in Table 1. For C. neoformans, the MIC values ranged from 7.81 to $62.5 \mu \mathrm{g} / \mathrm{mL}$ for SMX and 1.56 to $12.5 \mu \mathrm{g} / \mathrm{mL}$ for TMP; 15.63 to $500 \mu \mathrm{g} / \mathrm{mL}$ for SDZ and 0.781 to $25 \mu \mathrm{g} / \mathrm{mL}$ for PYR. For $C$. gattii, the MIC values were higher $(p<0.001)$ and ranged as follows: 62.5 to $250 \mu \mathrm{g} / \mathrm{mL}$ for SMX and 12.5 to $50 \mu \mathrm{g} / \mathrm{mL}$ for TMP; 125 to $500 \mu \mathrm{g} / \mathrm{mL}$ for SDZ and 6.25 to $25 \mu \mathrm{g} / \mathrm{mL}$ for PYR.

After pre-exposure to sub-MIC concentrations of SMX/ TMP and SDZ/PYR, strains of $C$. neoformans and $C$. gattii showed a decrease in MIC values of AMB $(p<0.05)$ (Table 2).

Effect of antifolate drug combinations on ergosterol content of planktonic cells

Sub-inhibitory concentrations of SMX/TMP and SDZ/PYR were also able to decrease the ergosterol content of Cryptococcus isolates $(p<0.05)$ (Fig. 1). No significant differences in the mean amount of total ergosterol between $C$. neoformans and C. gattii grown in SMX/TMP or SDZ/PYR were observed.

Effect of antifolate drug combinations against Cryptococcus biofilms

The antifolate drugs were able to inhibit mature Cryptococcus biofilms by up to $90 \%$ (Fig. 2). In addition, SMX/TMP and SDZ/PYR caused a reduction of approximately $80 \%$ in the biofilm formation (Fig. 3) of both C. neoformans and $C$. gattii. There were no further statistically significant differences between antifolate drugs and AMB at any concentration $(p>0.05)$ in both experiments.

\section{Discussion}

In recent years, several studies have shown the potential of antifungal drugs to inhibit folic acid synthesis in Candida albicans [30], Paracoccidioides brasiliensis [31], Histoplasma capsulatum [32], Coccidioides posadasii [26], and Aspergillus spp. [24]. Additionally, the combination SMX/
Table 1 Susceptibility profile of Cryptococcus planktonic cells to antifolate drugs

\begin{tabular}{|c|c|c|c|}
\hline \multirow[t]{2}{*}{ Strain } & \multirow[t]{2}{*}{ Species } & \multicolumn{2}{|l|}{$\mathrm{MIC}(\mu \mathrm{g} / \mathrm{mL})$} \\
\hline & & SMX/TMP & SDZ/PYR \\
\hline 03-02-062 & C. gattii & $125.0 / 25.0$ & $500.0 / 25.0$ \\
\hline 03-02-069 & C. gattii & $125.0 / 25.0$ & $250.0 / 12.5$ \\
\hline 03-02-070 & C. gattii & $62.5 / 12.5$ & $125.0 / 6.25$ \\
\hline 03-02-071 & C. gattii & $62.5 / 12.5$ & $250.0 / 12.5$ \\
\hline 03-02-073 & C. gattii & $250.0 / 50.0$ & $500.0 / 25.0$ \\
\hline $05-03-028$ & C. gattii & $125.0 / 25.0$ & $250.0 / 12.5$ \\
\hline 05-03-029 & C. gattii & $125.0 / 25.0$ & $250.0 / 12.5$ \\
\hline 05-03-030 & C. gattii & $62.5 / 12.5$ & $125.0 / 6.25$ \\
\hline 05-03-031 & C. gattii & $125.0 / 25.0$ & $125.0 / 6.25$ \\
\hline $05-03-032$ & C. gattii & $125.0 / 25.0$ & $250.0 / 12.5$ \\
\hline $05-03-033$ & C. gattii & $125.0 / 25.0$ & $125.0 / 6.25$ \\
\hline 03-02-074 & C. gattii & $125.0 / 25.0$ & $250.0 / 6.25$ \\
\hline $05-02-080$ & C. gattii & $125.0 / 25.0$ & $250.0 / 12.5$ \\
\hline 05-03-037 & C. gattii & $250.0 / 25.0$ & $500.0 / 6.25$ \\
\hline $05-02-082$ & C. gattii & $125.0 / 25.0$ & $250.0 / 12.5$ \\
\hline \multicolumn{2}{|c|}{ Geometric mean } & $119.4 / 22.79$ & $238.7 / 10.39$ \\
\hline $03-02-057$ & C. neoformans & $15.625 / 3.125$ & $62.5 / 3.125$ \\
\hline 03-02-061 & C. neoformans & $31.25 / 6.25$ & $15.625 / 0.781$ \\
\hline 03-02-068 & C. neoformans & $62.5 / 12.5$ & $125.0 / 6.25$ \\
\hline 03-02-072 & C. neoformans & $31.25 / 6.25$ & $15.625 / 0.781$ \\
\hline 05-01-050 & C. neoformans & $31.25 / 6.25$ & $62.5 / 3.125$ \\
\hline 03-02-060 & C. neoformans & $31.25 / 6.25$ & $62.5 / 3.125$ \\
\hline $03-02-063$ & C. neoformans & $62.5 / 12.5$ & $125.0 / 6.25$ \\
\hline 03-02-064 & C. neoformans & $15.625 / 3.125$ & $125.0 / 6.25$ \\
\hline $03-02-065$ & C. neoformans & $31.25 / 6.25$ & $62.5 / 3.125$ \\
\hline 03-02-066 & C. neoformans & $7.81 / 1.56$ & $500.0 / 25.0$ \\
\hline $03-02-067$ & C. neoformans & $15.625 / 3.12$ & $62.5 / 3.125$ \\
\hline $03-02-075$ & C. neoformans & $15.625 / 3.12$ & $62.5 / 3.125$ \\
\hline $03-02-078$ & C. neoformans & $31.25 / 6.25$ & $125.0 / 6.25$ \\
\hline 03-02-080 & C. neoformans & $15.625 / 3.12$ & $125.0 / 6.25$ \\
\hline 03-02-084 & C. neoformans & $15.625 / 1.56$ & $62.5 / 3.125$ \\
\hline \multicolumn{2}{|c|}{ Geometric mean } & $23.68 / 4.52$ & $75.19 / 5.96$ \\
\hline \multicolumn{4}{|c|}{ Reference strains } \\
\hline WM148 & C. neoformans & $3.906 / 0.78$ & $31.25 / 1.562$ \\
\hline WM626 & C. neoformans & $3.906 / 0.78$ & $31.25 / 1.562$ \\
\hline WM628 & C. neoformans & $3.906 / 0.78$ & $15.625 / 0.78$ \\
\hline WM629 & C. neoformans & $7.81 / 1.56$ & $31.25 / 1.562$ \\
\hline WM179 & C. gattii & $250.0 / 50.0$ & $250.0 / 12.5$ \\
\hline WM178 & C. gattii & $125.0 / 25.0$ & $250.0 / 12.5$ \\
\hline WM161 & C. gattii & $125.0 / 25.0$ & $250.0 / 12.5$ \\
\hline WM779 & C. gattii & $125.0 / 25.0$ & $250.0 / 12.5$ \\
\hline \multicolumn{2}{|c|}{ Geometric mean } & $26.28 / 5.25$ & $81.05 / 22.78$ \\
\hline
\end{tabular}

$S M X$ sulfamethoxazole, TMP trimethoprim, $S D Z$ sulfadiazine, $P Y R$ pyrimethamine 
Table 2 Effect of pre-exposure to folate inhibitors on the antifungal susceptibility of Cryptococcus planktonic cells

SMX sulfamethoxazole, TMP trimethoprim, $S D Z$ sulfadiazine, $P Y R$ pyrimethamine, $A M B$ amphotericin B

${ }^{\text {a }}$ Pre-exposure to folate inhibitors, followed by microdilution test to $\mathrm{AMB}$

\begin{tabular}{|c|c|c|c|c|}
\hline \multirow[t]{2}{*}{ Strain } & \multirow[t]{2}{*}{ Species } & \multicolumn{3}{|c|}{ MIC $(\mu \mathrm{g} / \mathrm{mL})$} \\
\hline & & AMB & $\mathrm{SMX} / \mathrm{TMP} \mathrm{AMB}^{\mathrm{a}}$ & $\mathrm{SDZ} / \mathrm{PYR} \mathrm{AMB}^{\mathrm{a}}$ \\
\hline $03-02-057$ & C. neoformans & 1.25 & 0.3125 & 0.625 \\
\hline $03-02-060$ & C. neoformans & 0.25 & 0.125 & 0.125 \\
\hline $03-02-063$ & C. neoformans & 0.156 & 0.078 & 0.078 \\
\hline $03-02-067$ & C. neoformans & 1.25 & 0.3125 & 0.625 \\
\hline $03-02-068$ & C. neoformans & 1.25 & 0.156 & 0.3125 \\
\hline $03-02-072$ & C. neoformans & 0.5 & 0.0625 & 0.125 \\
\hline $05-02-075$ & C. neoformans & 1.25 & 0.3125 & 0.156 \\
\hline $03-02-062$ & C. gattii & 0.625 & 0.3125 & 0.312 \\
\hline 03-02-069 & C. gattii & 1.25 & 0.156 & 0.3125 \\
\hline $03-02-073$ & C. gattii & 2.5 & 0.156 & 0.625 \\
\hline 05-03-029 & C. gattii & 0.5 & 0.125 & 0.125 \\
\hline 05-03-030 & C. gattii & 1.0 & 0.125 & 0.25 \\
\hline 05-03-031 & C. gattii & 1.0 & 0.125 & 0.125 \\
\hline $05-03-032$ & C. gattii & 0.5 & 0.125 & 0.25 \\
\hline
\end{tabular}

TMP has been used for years to treat paracoccidioidomycosis in Latin America [31], as well as for the treatment and prevention of Pneumocystis jiroveci pneumonia (PCP) in AIDS patients [33].

The present study shows that the combinations SMX/ TMP and SDZ/PYR - in the same ratio in which they are administered in vivo (1:5) - have antifungal activity against C. neoformans and C. gattii planktonic cells and are also able to enhance AMB activity. The antifungal activity of sulfa drugs on Cryptococcus was previously demonstrated by Hanafy et al. [24], who investigated the inhibitory effect of nine different sulfa drugs against a small number of Cryptococcus strains and concluded that SMX showed promising results.

In this study, SMX was able to inhibit the growth of $C$. neoformans and C. gattii at concentrations of $6.23 \mu \mathrm{g} / \mathrm{mL}$ and $119.3 \mu \mathrm{g} / \mathrm{mL}$, respectively, while Hanafy et al. [24] showed MIC values of up to $64 \mu \mathrm{g} / \mathrm{mL}$ for $C$. neoformans

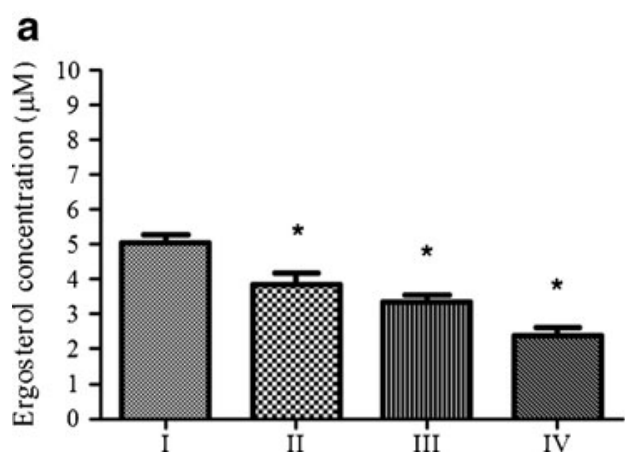

Fig. 1 Ergosterol content of C. neoformans (a) and C. gattii (b). Cells were cultured in YNB medium without antimicrobials as control $(I)$ or supplemented with SMX/TMP MIC/2 (II), SDZ/PYR MIC/2 (III), or and $>250 \mu \mathrm{g} / \mathrm{mL}$ for $C$. gattii. Possibly, this reduction in the MIC value is due to the synergistic effect of the drug with TMP. This study also shows that the SMX/TMP combination was more effective than SDZ/PYR.

Although the great majority of clinical and environmental isolates of Cryptococcus are sensitive to antifungals, the past decade has seen the emergence of resistant isolates in vitro to AMB and azoles [5, 6, 27]. In addition, the literature has reported the occurrence of strains of $C$. gattii with moderate resistance to FLC, ITC, and 5-fluorocytosine, as well as strains of $C$. neoformans with primary resistance to AMB, FLC, and voriconazole [5, 6, 34]. Given this scenario, researchers have attempted to find new antifungal drugs and to formulate strategies to increase the microbial sensitivity to antifungal agents for therapeutic use. This study demonstrates that pre-exposure to sub-MIC doses of antifolate drugs was able to increase the sensitivity of Cryptococcus to AMB. Discrete reduction (albeit statistically

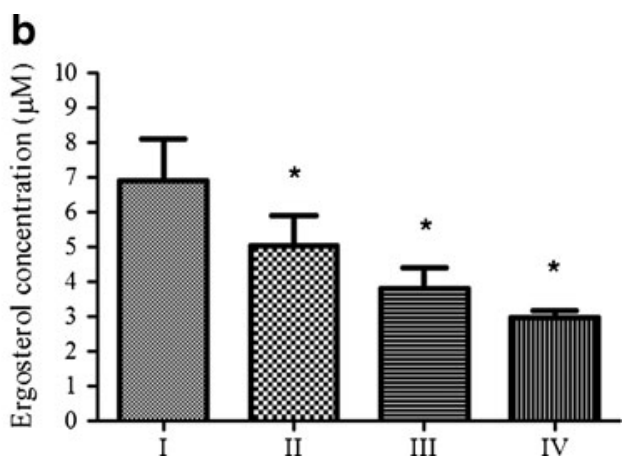

ITC MIC/2 (IV). The experiments were conducted in duplicate and the data are expressed as mean $\pm \operatorname{SEM}(n=7)$. The asterisks indicate statistically significant differences from controls $(p<0.05)$ 


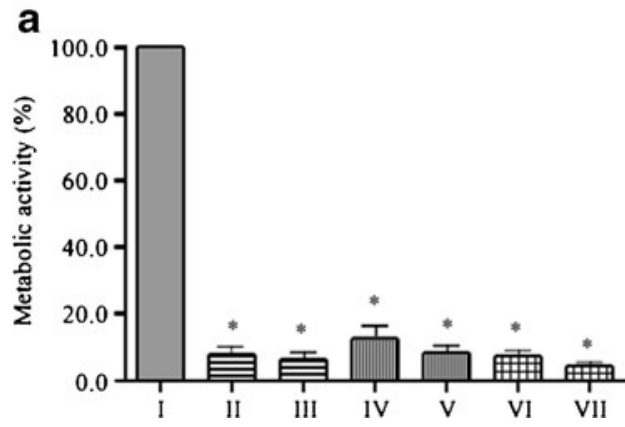

Fig. 2 Metabolic activity of C. neoformans (a) and C. gattii (b) biofilms when treated with different concentrations of antifolate drugs. Biofilms were grown in defined chemical medium without antimicrobials as controls $(I)$ and, after $48 \mathrm{~h}$, were tested against SMX/TMP at $2,000 \mathrm{mg} / \mathrm{L}-400 \mathrm{mg} / \mathrm{L}(I I), \mathrm{SMX} / \mathrm{TMP}$ at $5,000 \mathrm{mg} / \mathrm{L}-1,000 \mathrm{mg} / \mathrm{L}$ (III), SDZ/PYR at 2,000 mg/L-100 mg/L (IV), SDZ/PYR at 5,000 mg/

relevant) of itraconazole and fluconazole MICs was also detected after pre-exposure to sub-MIC doses of SMX/ TMP and SDZ/PYR (data not shown).

The data from this study show that the antifolate drugs cause a reduction in the cellular content of ergosterol in $C$. neoformans and $C$. gattii equivalent to that promoted by ITC, a drug that damages the synthesis of ergosterol. Navarro-Martínez et al. [30] suggested that, in C. albicans, folate inhibitors can inhibit S-adenosylmethionine (SAM), an enzyme cofactor which depends on sterol-C24methyltransferase and that acts on the ergosterol biosynthetic pathway. It is possible that the reduction of ergosterol content in Cryptococcus occurs by a similar mechanism.

In this study, two important aspects of the anti-biofilm potential of folate inhibitor drugs were evaluated: the ability to prevent biofilm formation and the action of the mature biofilm. By employing an in vitro model with high reproducibility, as recommended by Martinez et al. [9], it was possible to demonstrate that SMX/TMP and SDZ/PYR have

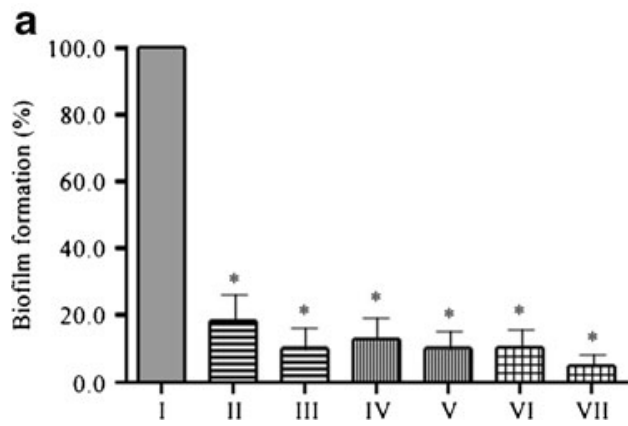

Fig. 3 Inhibition of biofilm formation in C. neoformans (a) and $C$. gattii (b). Biofilms were grown in defined chemical medium without antimicrobials as controls $(I)$ or supplemented with SMX/TMP at $2,000 \mathrm{mg} / \mathrm{L}-400 \mathrm{mg} / \mathrm{L}(I I), \mathrm{SMX} / \mathrm{TMP}$ at $5,000 \mathrm{mg} / \mathrm{L}-1,000 \mathrm{mg} / \mathrm{L}$ (III), SDZ/PYR at 2,000 mg/L-100 mg/L (IV), SDZ/PYR at $5,000 \mathrm{mg} /$ b

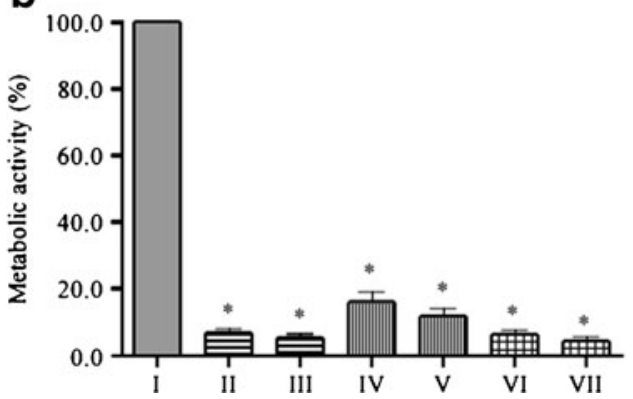

$\mathrm{L}-250 \mathrm{mg} / \mathrm{L}(V), \mathrm{AMB}$ at $64 \mathrm{mg} / \mathrm{L}(V I)$, or AMB at $150 \mathrm{mg} / \mathrm{L}(V I I)$. The results are represented as the percentage of reduction in comparison with controls. The experiments were conducted in duplicate and the data are expressed as mean $\pm \operatorname{SEM}(n=7)$. The asterisks indicate statistically significant differences from controls $(p<0.05)$

an anti-biofilm effect, acting on the two mechanisms investigated. Under the conditions tested, SMX/TMP and SDZ/ PYR showed inhibitory activity similar to that of AMB at $64 \mathrm{mg} / \mathrm{L}$, whose action on Cryptococcus biofilms has been previously described [14]. The results presented here are of great importance, given the high resistance of Cryptococcus biofilms to antifungal drugs for therapeutic use, such as FLC and voriconazole [14].

Although the antifolate combinations had shown a considerable anti-biofilm activity, we are aware that the concentrations tested in this study were above the therapeutic doses of each drug. However, it is possible that these concentrations may be attainable in catheters by way of intraluminal lock therapy.

Our results allow us to conclude that the combinations SMX/TMP and SDZ/PYR inhibit the growth of planktonic cells of $C$. neoformans and $C$. gattii, reduce their content of ergosterol, and increase their susceptibility to AMB. The drugs tested were able to prevent biofilm formation and also

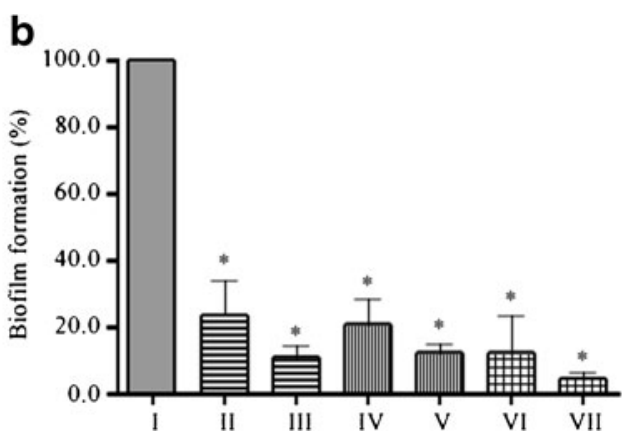

$\mathrm{L}-250 \mathrm{mg} / \mathrm{L}(V), \mathrm{AMB}$ at $64 \mathrm{mg} / \mathrm{L}(V I)$, or $\mathrm{AMB}$ at $150 \mathrm{mg} / \mathrm{L}(V I I)$. The results are represented as the percentage of reduction in comparison with controls. The experiments were conducted in duplicate and the data are expressed as mean $\pm \operatorname{SEM}(n=7)$. The asterisks indicate statistically significant differences from controls $(p<0.05)$ 
to significantly reduce the survival of cells in biofilm. Further studies in vivo are needed to confirm the usefulness of these results.

Funding declaration This work was supported by grants from the National Council for Scientific and Technological Development (CNPq; Brazil; Processes 302574/2009-3 and 562296/2010-7). We would like to thank the Mycology Laboratory of the Evandro Chagas Clinical Research Institute in Rio de Janeiro (IPEC/FIOCRUZ) for providing the reference strains from its cryptococcal culture collection.

Conflict of interest The authors declare that they have no conflict of interest.

\section{References}

1. Lin X, Heitman J (2006) The biology of the Cryptococcus neoformans species complex. Annu Rev Microbiol 60:69-105

2. Perfect JR, Dismukes WE, Dromer F, Goldman DL, Graybill JR, Hamill RJ, Harrison TS, Larsen RA, Lortholary O, Nguyen MH, Pappas PG, Powderly WG, Singh N, Sobel JD, Sorrell TC (2010) Clinical practice guidelines for the management of cryptococcal disease: 2010 update by the Infectious Diseases Society of America. Clin Infect Dis 50(3):291-322

3. Park BJ, Wannemuehler KA, Marston BJ, Govender N, Pappas PG, Chiller TM (2009) Estimation of the current global burden of cryptococcal meningitis among persons living with HIV/AIDS. AIDS 23(4):525-530

4. Brouwer AE, Rajanuwong A, Chierakul W, Griffin GE, Larsen RA, White NJ, Harrison TS (2004) Combination antifungal therapies for HIV-associated cryptococcal meningitis: a randomised trial. Lancet 363(9423):1764-1767

5. Varma A, Kwon-Chung KJ (2010) Heteroresistance of Cryptococcus gattii to fluconazole. Antimicrob Agents Chemother 54 (6):2303-2311

6. Perkins A, Gomez-Lopez A, Mellado E, Rodriguez-Tudela JL, Cuenca-Estrella M (2005) Rates of antifungal resistance among Spanish clinical isolates of Cryptococcus neoformans var. neoformans. J Antimicrob Chemother 56(6):1144-1147

7. Bii CC, Makimura K, Abe S, Taguchi H, Mugasia OM, Revathi G, Wamae NC, Kamiya S (2007) Antifungal drug susceptibility of Cryptococcus neoformans from clinical sources in Nairobi, Kenya. Mycoses 50(1):25-30

8. Sionov E, Chang YC, Garraffo HM, Kwon-Chung KJ (2009) Heteroresistance to fluconazole in Cryptococcus neoformans is intrinsic and associated with virulence. Antimicrob Agents Chemother 53(7):2804-2815

9. Martinez LR, Mihu MR, Han G, Frases S, Cordero RJ, Casadevall A, Friedman AJ, Friedman JM, Nosanchuk JD (2010) The use of chitosan to damage Cryptococcus neoformans biofilms. Biomaterials 31(4):669-679

10. Steverding D, Evans P, Msika L, Riley B, Wallington J, Schelenz S (2012) In vitro antifungal activity of DNA topoisomerase inhibitors. Med Mycol 50(3):333-336

11. Verwer PE, Woodle MC, Boekhout T, Hagen F, BakkerWoudenberg IA, van de Sande WW (2011) Cryptococcus and Trichosporon spp. are susceptible in vitro to branched histidineand lysine-rich peptides (BHKPs). J Antimicrob Chemother 66 (7):1649-1652
12. Martinez LR, Casadevall A (2007) Cryptococcus neoformans biofilm formation depends on surface support and carbon source and reduces fungal cell susceptibility to heat, cold, and UV light. Appl Environ Microbiol 73(14):4592-4601

13. Ramage G, Mowat E, Jones B, Williams C, Lopez-Ribot J (2009) Our current understanding of fungal biofilms. Crit Rev Microbiol 35(4):340-355

14. Martinez LR, Casadevall A (2006) Cryptococcus neoformans cells in biofilms are less susceptible than planktonic cells to antimicrobial molecules produced by the innate immune system. Infect Immun 74(11):6118-6123

15. Martinez LR, Casadevall A (2006) Susceptibility of Cryptococcus neoformans biofilms to antifungal agents in vitro. Antimicrob Agents Chemother 50(3):1021-1033

16. Robertson EJ, Wolf JM, Casadevall A (2012) EDTA inhibits biofilm formation, extracellular vesicular secretion, and shedding of the capsular polysaccharide glucuronoxylomannan by Cryptococcus neoformans. Appl Environ Microbiol 78(22):7977-7984

17. Walsh TJ, Schlegel R, Moody MM, Costerton JW, Salcman M (1986) Ventriculoatrial shunt infection due to Cryptococcus neoformans: an ultrastructural and quantitative microbiological study. Neurosurgery 18(3):373-375

18. Ingram CW, Haywood HB 3rd, Morris VM, Allen RL, Perfect JR (1993) Cryptococcal ventricular-peritoneal shunt infection: clinical and epidemiological evaluation of two closely associated cases. Infect Control Hosp Epidemiol 14(12):719-722

19. Banerjee U, Gupta K, Venugopal P (1997) A case of prosthetic valve endocarditis caused by Cryptococcus neoformans var. neoformans. J Med Vet Mycol 35(2):139-141

20. Johannsson B, Callaghan JJ (2009) Prosthetic hip infection due to Cryptococcus neoformans: case report. Diagn Microbiol Infect Dis 64(1):76-79

21. Cordeiro RA, Costa AK, Brilhante RS, de Lima RA, CasteloBranco Dde S, Ribeiro JF, Monteiro AJ, Rocha FA, Sidrim JJ, Rocha MF (2011) PCR-REA as an important tool for the identification of Cryptococcus neoformans and Cryptococcus gattii from human and veterinary sources. Vet Microbiol 154(1-2):180-184

22. Enache-Angoulvant A, Chandenier J, Symoens F, Lacube P, Bolognini J, Douchet C, Poirot JL, Hennequin C (2007) Molecular identification of Cryptococcus neoformans serotypes. J Clin Microbiol 45(4):1261-1265

23. Meyer W, Castañeda A, Jackson S, Huynh M, Castañeda E; IberoAmerican Cryptococcal Study Group (2003) Molecular typing of IberoAmerican Cryptococcus neoformans isolates. Emerg Infect Dis 9(2):189-195

24. Hanafy A, Uno J, Mitani H, Kang Y, Mikami Y (2007) In vitro antifungal activities of sulfa drugs against clinical isolates of Aspergillus and Cryptococcus species. Jpn J Med Mycol 48 (1):47-50

25. Clinical and Laboratory Standards Institute (CLSI) (2008) Reference method for broth dilution antifungal susceptibility testing of yeasts; approved standard - third edition. CLSI document M27A3. CLSI, Wayne, PA

26. Cordeiro Rde A, Astete-Medrano DJ, Marques FJ, Andrade HT, Perdigão Neto LV, Tavares JL, de Lima RA, Patoilo KK, Monteiro AJ, Brilhante RS, Rocha MF, de Camargo ZP, Sidrim JJ (2011) Cotrimoxazole enhances the in vitro susceptibility of Coccidioides posadasii to antifungals. Mem Inst Oswaldo Cruz 106(8):1045-1048

27. Costa AK, Sidrim JJ, Cordeiro RA, Brilhante RS, Monteiro AJ, Rocha MF (2010) Urban pigeons (Columba livia) as a potential source of pathogenic yeasts: a focus on antifungal susceptibility of Cryptococcus strains in Northeast Brazil. Mycopathologia 169 (3):207-213

28. Moran GP, Pinjon E, Coleman DC, Sullivan DJ (2007) Analysis of drug resistance in pathogenic fungi. In: Kavanagh K (ed) Medical 
mycology: cellular and molecular techniques. Wiley, Hoboken, pp 93-113

29. Peeters E, Nelis HJ, Coenye T (2008) Comparison of multiple methods for quantification of microbial biofilms grown in microtiter plates. J Microbiol Methods 72(2):157-165

30. Navarro-Martínez MD, Cabezas-Herrera J, Rodríguez-López JN (2006) Antifolates as antimycotics? Connection between the folic acid cycle and the ergosterol biosynthesis pathway in Candida albicans. Int J Antimicrob Agents 28(6):560-567

31. Hahn RC, Morato Conceição YT, Santos NL, Ferreira JF, Hamdan JS (2003) Disseminated paracoccidioidomycosis: correlation between clinical and in vitro resistance to ketoconazole and trimethoprim sulphamethoxazole. Mycoses 46(8):342-347

32. Brilhante RS, Fechine MA, Cordeiro Rde A, Rocha MF, Ribeiro JF, Monteiro AJ, de Lima RA, Mesquita JR, de Camargo ZP, Sidrim JJ (2010) In vitro effect of sulfamethoxazole-trimethoprim against Histoplasma capsulatum var. capsulatum. Antimicrob Agents Chemother 54(9):3978-3979

33. Lim PL, Zhou J, Ditangco RA, Law MG, Sirisanthana T, Kumarasamy N, Chen YM, Phanuphak P, Lee CK, Saphonn V, Oka S, Zhang F, Choi JY, Pujari S, Kamarulzaman A, Li PC, Merati TP, Yunihastuti E, Messerschmidt L, Sungkanuparph S; TREAT Asia HIV Observational Database (2012) Failure to prescribe pneumocystis prophylaxis is associated with increased mortality, even in the cART era: results from the Treat Asia HIV observational database. J Int AIDS Soc 15:1

34. Pfaller MA, Boyken L, Hollis RJ, Messer SA, Tendolkar S, Diekema DJ (2005) In vitro susceptibilities of clinical isolates of Candida species, Cryptococcus neoformans, and Aspergillus species to itraconazole: global survey of 9,359 isolates tested by clinical and laboratory standards institute broth microdilution methods. J Clin Microbiol 43(8):3807-3810 